\title{
PERFORMANCE AND OPTIMIZATION OF 304 L STAINLESS STEEL IN RADIAL DRILLING MACHINE
}

\author{
Arjun PR \\ Research Assistant \\ SSIAR Bangalore
}

\begin{abstract}
The challenge of modern machining industries is focused mainly on the achievement of high quality, in terms of work piece dimensional accuracy, surface finish, high production rate, lubrication medium, vibration of tool, less wear on the cutting tools, economy of machining in terms of cost saving and increase the performance of the product with reduced environmental impact. In metal cutting industries, surface roughness (SR) of a product is very crucial in determining the quality. Good SR not only assures quality, but also reduces manufacturing cost. In machining operation, the quality of SR is an important requirement for many turned work pieces. In Drilling operation, there are many parameters such as cutting speed, depth of cut, point angle, vibration of tool and feed rate that have great impact on the SR.

The quality of the drilled part is greatly influenced by the cutting conditions, tool geometry, tool material, machining process, chip formation, work piece material, tool wear, and vibration during cutting, etc. Thus in material removal processes, improper selection of cutting conditions will result in rough surfaces. Moreover, it is necessary to optimize the cutting parameters to obtain an extended tool life and better productivity, which are influenced by cutting force.

Hence in this work, experimental works were conducted on $304 \mathrm{~L}$ Stainless Steel for optimal setting of drilling parameters such as cutting speed, feed, lubricating medium and point angle with the objective of minimization of surface roughness, cutting force, vibration of tool, tool wear, tool temperature and torque. The selected drill was TiN coated HSS twist drill grade. The drilling process carried out as dry machining.
\end{abstract}

Index Terms - radial drilling, optimization, 304L stainless steel, tool wear, surface roughness

\section{INTRODUCTION}

Drilling is the primary operation in most of the production process in the industry, surface finish of turned components has greater influence on the quality of the product Surface finish in turning has been found to be influenced in varying amounts by a number of factors such as feed rate, work hardness, unstable built up edge, speed, depth of cut, cutting time, use of cutting fluids etc.

There are three primary input control parameters in the basic drilling operations. They are feed, spindle speed and depth of cut. Feed is the rate at which the tool advances along its cutting path. Speed always refers to the spindle and the work piece. Depth of cut is the thickness of the material that is removed by one pass of the cutting tool over the work piece. Machinability refers to the ease with which a metal can be machined to an acceptable surface finish. Materials with good Machinability required little power to cut, can be cut quickly, easily obtained a good finish, and do not wear the tooling much; such materials are said to be free machining. The factor that typically improve a material's performance often degrades its Machinability.

Therefore to manufacture component economically, engineers are challenged to find ways to improve machinability without harming performance. 304 L stainless steel (304 L SS) is a material with better corrosion resistance and mechanical properties. It is apparent that a balance of ferrite or austenite phase in a microstructure made it realistic for applications which demand better corrosion resistance and improved mechanical properties. Alloy 304L a T-300 series stainless steel austenitic, which has a minimum of $18 \%$ chromium and $8 \%$ nickel. Type $304 \mathrm{~L}$ has a carbon maximum is 0.030 . It is the standard " $18 / 8$ stainless" that is commonly found in pans and cooking tools. Alloys 304L is the most versatile and widely used alloy in the stainless steel family. Ideal for a wide variety of home and commercial applications, Alloys 304L exhibits excellent corrosion resistance and has a high ease of 
fabrication, outstanding formability. The austenitic stainless steels are also considered to be the most machinable of the high-alloy steels and can be welded by all fusion and resistance welding processes.

In areas in which similar drilling practices are used, hole problems may have been reported where no such problems existed previously because formations are nonhomogeneous. Understanding and anticipating drilling problems, understanding their causes, and planning solutions are necessary for overall-well-cost control and for successfully reaching the target zone. Drilling is the primary operation in most of the production processes in the industry. In this operation, it is an important task to select cutting parameters for achieving high cutting performance. The cutting parameters that determine the quality of surface, rate of metal removal and cutting performance are the cutting speed, the feed rate, and the depth of cut. These cutting conditions and the nature of the material to be cut determine the power required to take the cut. On the other hand these parameters are influential on production cost, machining time and quality of the final product. Improper selection of cutting parameters will lead to severe quality loss and increased cost of manufacturing. So these parameters needed to be optimized to obtain desired surface quality with reduced machining time and cost. So the objective is to find the optimum cutting condition to get desired surface quality.

$>$ The inner portion of the drilled hole will be not smooth as required because of the larger vibration of tool.

$>$ The chance of defect formation such chip formations, increase tool temperature, surface roughness.

$>$ Productivity quality is much lesser for conventional steel because of the presence of blow holes present in the material.

$>$ Quickly breakdown of drill bit because of improper speed and point of contact.

\section{METHODOLOGY}

\section{TAGUCHI METHOD}

Dr. Taguchi of Nippon Telephones and Telegraph Company, Japan has developed a method based on "ORTHOGONAL ARRAY" experiments which gives much reduced "variance" for the experiment with "optimum settings" of control parameters. Thus the marriage of Design of Experiments with optimization of control parameters to obtain BEST results is achieved in the Taguchi Method. "Orthogonal Arrays" (OA) provide a set of well balanced (minimum) experiments and Dr. Taguchi's Signal-to-Noise ratios $(\mathrm{S} / \mathrm{N})$, which are log functions of desired output, serve as objective functions for optimization, help in data analysis and prediction of optimum results. There are 3 Signal-to-Noise ratios of common interest for optimization problems;

\section{SMALLER-THE-BETTER}

$\mathrm{n}=-10 \log _{10}$ [mean of sum of squares of measured data]

This is usually the chosen $\mathrm{S} / \mathrm{N}$ ratio for all undesirable characteristics like "defects" etc. for which the ideal value is zero. Also, when an ideal value is finite and its maximum or minimum value is defined (like maximum purity is $100 \%$ or maximum $\mathrm{Tc}$ is $92 \mathrm{~K}$ or minimum time for making a telephone connection is $1 \mathrm{sec}$ ) then the difference between measured data and ideal value is expected to be as small as possible. The generic form of $\mathrm{S} / \mathrm{N}$ ratio then becomes,

$n=-10 \log _{10}[$ mean of sum of squares of $\{$ measured - ideal $\}]$

\section{LARGER-THE-BETTER}

$n=-10 \log _{10}$ [mean of sum squares of reciprocal of measured data]

This case has been converted to SMALLER-THE-BETTER by taking the reciprocals of measured data and then taking the $\mathrm{S} / \mathrm{N}$ ratio as in the smaller-the-better case.

\section{NOMINAL-THE-BEST}

$$
\begin{gathered}
\text { Square of mean } \\
\mathrm{n}=10 \log _{10} \text {----------- } \\
\text { variance }
\end{gathered}
$$

This case arises when a specified value is MOST desired, meaning that neither a smaller nor a larger value is desirable.

It has excellent forming and welding characteristics. The balanced austenitic structure of grade 304 enables it to be severely deep drawn without intermediate annealing, which has made this grade dominant in the manufacture of drawn stainless parts. For these applications its common to use special drawing quality variants. Grade 304 is readily brake or roll formed into a variety of components for applications in the industrial, architectural, and transportation fields. Grade 304 also has outstanding welding characteristics. 
The surface roughness was measured at three positions spaced at 120degree intervals around the hole circumference with the cut off length $0.8 \mathrm{~mm}$ using SURFTEST 211 . The surface roughness of each hole was taken as the mean of three circumferential readings.

The cutting point of a standard HSS twist drills of $10 \mathrm{~mm}$ diameter were changed into various cutting points $(90,115$ and 140 degrees) and coated with TiN were used throughout the experiment work.

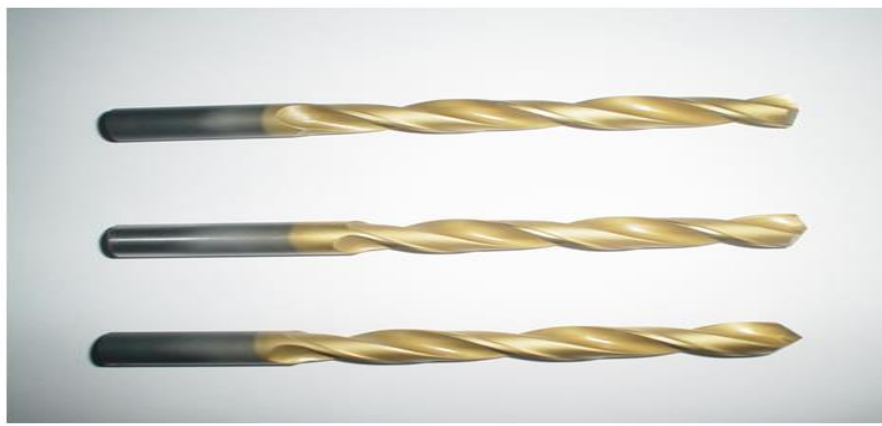

It is a device for measuring force, moment of force (torque), or power. For example, the power produced by an engine, motor or other rotating prime can be calculated by simultaneously measuring torque and rotational speed (rpm).

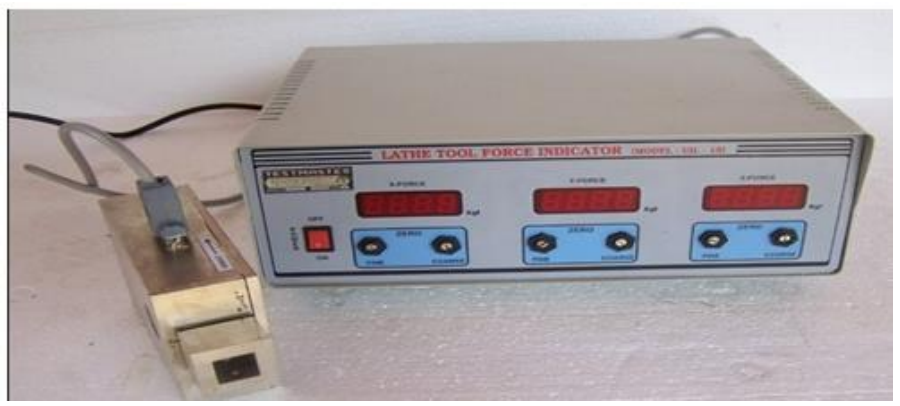

It will provides you high quality profile projectors and optical comparators for your manufacturing and quality control needs. With our tool makers microscope equipment, you can easily view ,measure, project, and draw complex contours and profiles. The large viewing projection screen is a great tool for teaching and demonstrating to all participants in the classroom. Each profile projector is selectable between incident (top) and contour can easily be traced or compared on a drawing held to the large projection screen by the included document holder clips.

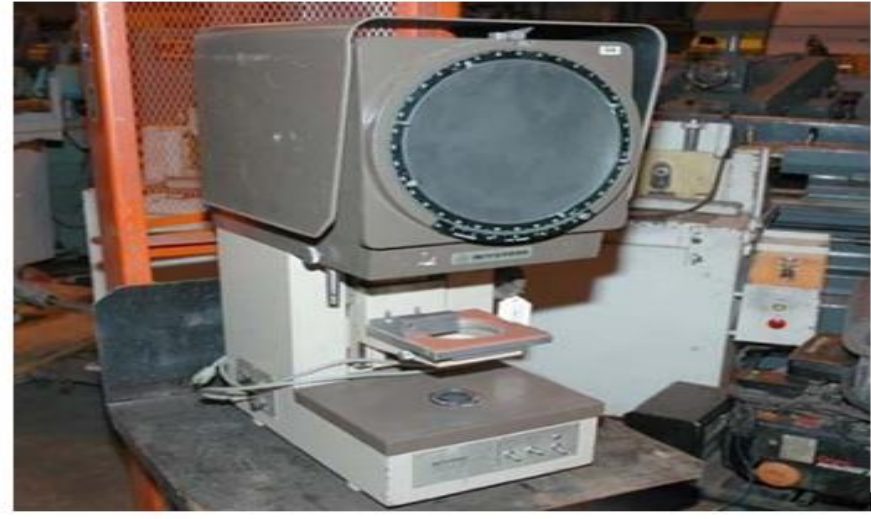

Surface roughness tester is a small sized, affordable portable surface roughness tester designed with an advanced microprocessor which performs data acquisition, data processing and display of all test measurements.

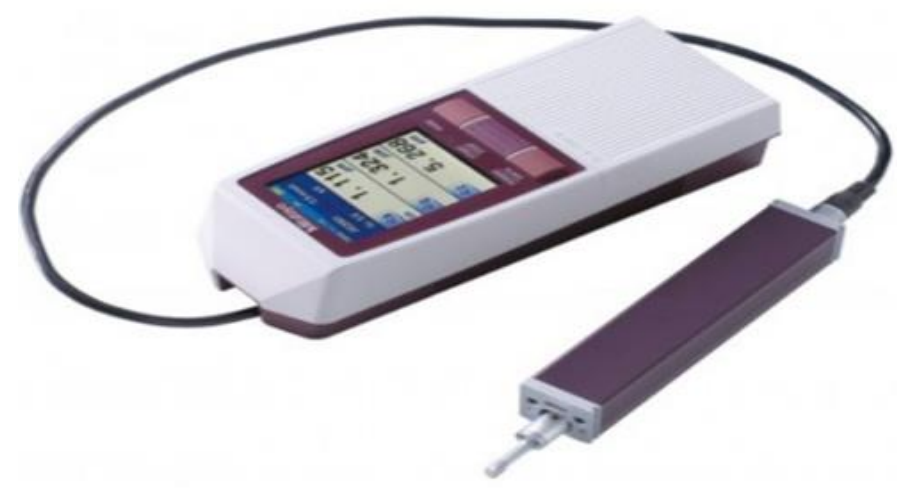

\section{FACTORS USED IN EXPERIMENT}

The most influencing factors that will affect the quality of hole are cutting speed, feed and point angle of drill. Hence in this work, cutting speed, feed and point angle of drill were identified as a factors for the objective of minimization of surface roughness, cutting force.

In this work, three factors each set at three levels were selected for the experimentation. The ranges of independent variables (factors) are selected based on the data book (Alok Nayar, 2002, CMTI, 2004 \& ASM hand book, 1989), the past experience and the available resources. 


\begin{tabular}{|c|c|c|c|c|}
\hline Factors & Unit & \multicolumn{3}{|c|}{ Levels } \\
& & 1 & 3 \\
\hline Cutting Speed & $\mathrm{m} / \mathrm{min}$ & 35.18 & 56.54 & 87.96 \\
(V) & & & & \\
Feed & $\mathrm{mm} / \mathrm{rev}$ & 0.05 & 0.125 & 0.200 \\
(F) & & & & \\
Point Angle & degree & 90 & 115 & 140 \\
(PA) & & & & \\
\hline
\end{tabular}

\section{SELECTION CRITERIA'S FOR ORTHOGONAL ARRAY}

Orthogonal array gives more reliable estimates of factor effects with less number of experiments, when compared to the traditional methods, such as one factor at a time experiments. There are 18 basic types of standard Orthogonal Array in the Taguchi parameter design (Torng et al, 1998 and Yang \& Chen, 2001). Since three factors were studied in this research, three levels of each factor were considered. For experimental work, Taguchi method of $\mathrm{L}_{9}$ orthogonal array was used at three factors at three levels. The factors chosen were cutting speed, feed and point angle of drill. With three factors at three levels, the total degrees of freedom are 8 . Hence $L_{9}$ orthogonal array having 8 degrees of freedom was selected for the controllable factors.

The conditions for selection of orthogonal array used in the experiment are

Degree of freedom (DOF) for factors : levels -1 . DOF for OA No. of trails -1 . DOF of L9 orthogonal array $9-1=8$

The orthogonal array is selected based on the following conditions.

$\sum \mathrm{DOF}_{\mathrm{i}} \leq \mathrm{DOF}$ of OA, number of factors : $\mathrm{i}=1$ to $\mathrm{n}$.

For three factors and three levels L9 orthogonal array is used.

Based on Taguchi's L ${ }_{9}$ OA, drilling experiments, have to be done on Stainless steel $304 \mathrm{~L}$ using HSS twist drill coated with TiN.

\section{Analysis of $\mathrm{S} / \mathrm{N}$ ratio}

Signal to Noise $(\mathrm{S} / \mathrm{N})$ ratios have to be calculated for all the responses. S/N ratio analysis have to be carried out to obtain the optimal setting condition for drilling of Stainless steel $304 \mathrm{~L}$ using Taguchi method. The $\mathrm{S} / \mathrm{N}$ ratio for smaller the better type category is given by the equation. The $\mathrm{S} / \mathrm{N}$ ratio for smaller the better type category is given by the equation,

$$
\eta=-10 \log _{10}\left\{\frac{1}{n} \sum_{i=1}^{n} y_{i}^{2}\right\}
$$

where $\mathrm{y}$ is the response and $\mathrm{n}$ is the number of replications of each trial i.

\section{Analysis of Means (ANOM)}

The data analysis procedure using Taguchi experimental framework involves ANOM and ANOVA. The ANOM helps in identifying the optimal setting of drilling parameter combinations. ANOVA establishes the relative significance of factors in terms of their percentage contribution to the response

\section{RESULTS AND DISCUSSIONS}

\section{ANOM for S/N ratio of Surface Roughness}

\begin{tabular}{ccccc}
\hline Factors & \multicolumn{5}{c}{ Levels } & Optimum \\
& $\mathbf{1}$ & $\mathbf{2}$ & $\mathbf{3}$ & \\
\hline $\mathrm{V}$ & -12.29 & -15.83 & -16.59 & $\mathrm{~V}_{1}$ \\
$\mathrm{~F}$ & -16.66 & -15.23 & -12.82 & $\mathrm{~F}_{3}$ \\
$\mathrm{PA}$ & -17.31 & -14.81 & -12.59 & $\mathrm{PA}_{3}$ \\
\hline
\end{tabular}

\begin{tabular}{|c|c|c|}
\hline Trial number & $\begin{array}{c}\text { Surface } \\
\text { roughness (Ra) } \\
\text { in } \mu \mathrm{m}\end{array}$ & $\begin{array}{l}\text { Responses } \\
\text { Cutting force } \\
\text { (Fc) in } \mathrm{N}\end{array}$ \\
\hline 1 & 7.83 & 107.87 \\
\hline 2 & 4.01 & 254.96 \\
\hline 3 & 2.22 & 470.67 \\
\hline 4 & 6.7 & 186.31 \\
\hline 5 & 5.8 & 539.33 \\
\hline 6 & 6.09 & 1186.53 \\
\hline 7 & 6.01 & 274.57 \\
\hline 8 & 8.27 & 1078.66 \\
\hline 9 & 6.2 & 1274.78 \\
\hline
\end{tabular}


$\mathrm{S} / \mathrm{N}$ ratio values for the responses $\mathrm{Ra}, \mathrm{Fc}$ and $\mathrm{T}$

\begin{tabular}{cccc}
\hline \multirow{2}{*}{ Trial number } & \multicolumn{3}{c}{$\mathbf{S} / \mathbf{N}$ (in dB) ratio for } \\
& Ra & Fc & T \\
\hline 1 & -17.875 & -40.66 & 1.11 \\
2 & -12.084 & -48.13 & -6.28 \\
3 & -06.927 & -53.45 & -7.08 \\
4 & -16.521 & -45.40 & -5.85 \\
5 & -15.268 & -54.64 & -2.14 \\
6 & -15.692 & -61.49 & -10.21 \\
7 & -15.577 & -48.77 & 3.22 \\
8 & -18.350 & -60.66 & -8.13 \\
9 & -15.847 & -62.11 & -6.69 \\
\hline
\end{tabular}

ANOM for $\mathrm{S} / \mathrm{N}$ ratio of cutting force

\begin{tabular}{|c|c|c|c|c|}
\hline \multirow{3}{*}{ Factors } & \multicolumn{3}{|c|}{ Levels } & \multirow{3}{*}{ Optimum } \\
\hline & & & & \\
\hline & 1 & 2 & 3 & \\
\hline $\mathrm{V}$ & -47.41 & -53.84 & -57.18 & $\mathrm{~V}_{1}$ \\
\hline F & -44.95 & -54.47 & -59.02 & $F_{1}$ \\
\hline $\mathrm{PA}$ & -54.27 & -51.88 & -52.29 & $\mathrm{PA}_{2}$ \\
\hline
\end{tabular}

For minimum surface roughness, first level of the cutting speed $(\mathrm{V})$, third level of feed $(\mathrm{F})$ and third level of point angle (PA) is the optimal setting parameters for drilling of $304 \mathrm{~L}$ stainless steel. So the optimal setting is $\mathrm{V}_{1}, \mathrm{~F}_{3}$, and $\mathrm{PA}_{3}$ for a minimum surface roughness.

Optimal setting parameter for minimum surface roughness, cutting force and torque.

\begin{tabular}{ccc}
\hline Sl. Number & Response & Optimal setting \\
& & parameters \\
\hline 1 & Surface roughness & $\mathrm{V}_{1}, \mathrm{~F}_{3}$, and $\mathrm{PA}_{3}$ \\
2 & Cutting force & $\mathrm{V}_{1}, \mathrm{~F}_{1}$, and $\mathrm{PA}_{2}$ \\
3 & Torque & $\mathrm{V}_{3}, \mathrm{~F}_{1}$, and $\mathrm{PA}_{3}$ \\
\hline
\end{tabular}

\section{CONCLUSION}

In this project Drilling experiments were conducted on a Radial drilling machine by HSS twist drill coated with $\mathrm{TiN}$ and $\mathrm{Al} / \mathrm{SiC} 10 \%$ by volume fraction metal matrix composites as work material. The data for surface roughness, cutting force and torque were collected under different cutting conditions for various combinations of drilling parameters. The following conclusions can be drawn.

- Taguchi method is powerful tool for optimization of single response problems and it provides a systematic and effective methodology for the design optimization of drilling parameters.

- The surface roughness value of $2.22 \mu \mathrm{m}$ was obtained with TiN coated HSS twist drill when drilling $304 \mathrm{~L}$ stainless steel with the higher cutting point angle of 140degree, higher feed of $0.2 \mathrm{~mm} / \mathrm{rev}$ and lower cutting speed of $35.18 \mathrm{~m} / \mathrm{min}$.

- For minimum cutting force, the optimal setting parameters are $\mathrm{V}_{1}(35.18 \mathrm{~m} / \mathrm{min}), \mathrm{F}_{1}(0.05 \mathrm{~mm} / \mathrm{rev})$, and $\mathrm{PA}_{2}$ (115 degree).

\section{REFERENCE}

[1] Diwakar Reddy.V, Krishnaiah.G. et al (2011), ANN Based Prediction of Surface Roughness in Turning, International Conference on Trends in Mechanical and Industrial Engineering (ICTMIE'2011) Bangkok.

[2] Mahapatra, S.S. et al (2006). Parametric Analysis and Optimization of Cutting Parameters for Turning Operations based on Taguchi Method, Proceedings of the International Conference on Global Manufacturing and Innovation - July 2729. 
[3] Suhail, Adeel H. et al (2010). Optimization of Cutting Parameters Based on Surface Roughness and Assistance of Workpiece Surface Temperature in Turning Process, American J. of Engineering and Applied Sciences 3 (1): 102-108.

[5] Van Luttervelt, C. A. et al (1998). Present situation and future trends in modelling of machining operations, CIRP Ann.

[6] Kirby, Daniel (2010). Optimizing the Turning Process toward an Ideal Surface Roughness Target.

[7] Selvaraj, D. Philip et al (2010). optimization of surface roughness of aisi 304 austenitic stainless steel in dry turning operation using Taguchi design method Journal of Engineering Science and Technology,Vol. 5, no. 3293 - 301, () school of engineering, Taylor's university college.

[8] Tosun, N., Ozler, L., 2000. A study of tool life in hot machining using artificial neural network and regression analysis. J. mat.proc.Technol. 124, 99-104.

[9] Wardancy, T.I.E., Elestawi, M.A., 1997. Prediction of tool failure rate in turning hardened steels. Int.J.manuf,Technol. 13, $1-16$.

[10] Selvam, M.S., 1975.Tool vibration and its influence on surface roughness in turning. 35, 149-157.

[11] Lasota, A., Rusek, P., 1983. Influence of random vibrations on the roughness of turned surfaces. J. Mech Work Technol. 7, 277-284.

[12Trent EM. 1989. Metal cutting. London, Butterworths Press. New York. 